\title{
PENGARUH ARANG SEKAM PADI DAN ARANG TONGKOL JAGUNG SEBAGAI MEDIA ADSORBEN DALAM PENURUNAN ZAT BESI (Fe) PADA AIR SUMUR GALI
}

The Effect Of Rice Husk Charcoal And Corn Cob Charcoal As Adsorbent Media In Reducing Iron (Fe) In Dug Well Water

Ronny, Ahmad Arzyl Alfajri

Program Studi Sanitasi Lingkungan, Poltekkes Kemenkes Makassar ronnymuntu@gmail.com/085255666746

\begin{abstract}
Clean water quality must be a very important concern, especially in overcoming the problem of high iron (Fe) in dug well water. Therefore, we need a simple medium that can overcome the problem of high iron (Fe) in dug well water, namely by using rice husk charcoal and corncob charcoal as adsorbent media in reducing iron (Fe) in dug well water. This type of research is a quasi-experimental. The purpose of this study was to determine the effect of rice husk charcoal and corncob charcoal as adsorbent media in reducing iron (Fe) in dug well water using up-flow filtration with the adsorption method.. The results of the study showed that the effect of rice husk charcoal in reducing iron (Fe) in dug well water could decrease with an average percentage decrease of $100 \%$ while corncob charcoal could reduce iron (Fe) with an average percentage decrease of $98.5 \%$.Based on the discussion, it can be concluded that when compared to corncob charcoal, rice husk charcoal media is the most effective in reducing iron (Fe) in well water. It is recommended to the public that these two media can be used, so that further research can consider using corncob charcoal due to the physical properties of the media which is easily saturated, and it is expected to use alternative materials that are easily available to the public to be used in carbon activation.
\end{abstract}

Keywords: Rice husk, Corn cob, Iron (Fe)

\section{ABSTRAK}

Kualitas air bersih harus menjadi perhatian yang sangat penting terutama dalam mengatasi asalah tingginya zat besi ( $\mathrm{Fe}$ ) pada Air sumur gali. Oleh karena itu, diperlukan suatu media sederhana yang dapat mengatasi masalah tingginya zat besi (Fe) pada air sumur gali, yaitu dengan menggunakan arang sekam padi dan arang tongkol jagung sebagai media adsorben dalam pengurunan zat besi (Fe) pada air sumur gali. Jenis penelitian ini adalah eksperimen semu. Tujuan dari penelitian ini yaitu untuk mengetahui pengaruh arang sekam padi dan arang tongkol jagung sebagai media adsorben dalam penurunan zat besi ( $\mathrm{Fe}$ ) pada air sumur gali menggunakan penyaringan secara up flow dengan metode adsorpsi. Hasil dari penelitian menunjukkan bahwa pengaruh arang sekam padi dalam penurunan zat besi (Fe) pada air sumur gali dapat menurunkan dengan rata-rata persentase penurunan sebesar $100 \%$ sedangkan arang tongkol jagung dapat menurunkan zat besi $(\mathrm{Fe})$ dengan rata rata persentase penurunan 98,5\%. Berdasarkan pembahasan dapat disimpulkan bahwa jika dibandingkan dengan arang tongkol jagung, media arang sekam padi paling efektif dalam mereduksi besi $(\mathrm{Fe})$ pada air sumur. Disarankan kepada masyarakat agar kedua media ini dapat digunakan, sehingga penelitian selanjutnya dapat mempertimbangkan untuk menggunakan arang tongkol jagung dikarenakan secara sifat fisik media yang mudah jenuh, dan diharapkan menggunakan bahan alternatif yang mudah didapatkan masyarakat digunakan dalam pengaktifan karbon.

Kata Kunci : sekam padi, tongkol jagung, Besi (Fe)

\section{PENDAHULUAN}

Sebagai Negara penduduk terpadat keempat di dunia, ketimpangan penyediaan air bersih di Indonesia menjadi isu penting karena mempengaruhi semua aspek kehidupan, mulai dari kesehatan hingga kesejahteraan masyarakat. Akses terhadap air bersih juga dianggap sebagai salah satu cara untuk memutus mata rantai kemiskinan. Sayangnya, semakin banyak orang kekurangan akses terhadap air bersih, 33,4 juta orang kekurangan air bersih, dan 99,7 juta orang tidak memiliki akses terhadap fasilitas sanitasi yang baik. Menurut data Badan Pusat Statistik (BPS), pencapaian Indonesia saat ini dalam memperoleh air bersih sudah mencapai $72,55 \%$. Angka tersebut masih di bawah target Sustainable Development Goals (SDG) yaitu 100\%. (Rossa, Vania,. dan Nadia, Fista, 2018)

Kementerian Dalam Negeri merilis data kependudukan semester I 2020 melalui Direktorat Jenderal Kependudukan dan Pencatatan Sipil (Dukcapil). Menurut data kependudukan, per 30 Juni jumlah penduduk Indonesia sebanyak 268.583.016 jiwa. (Nugraheny D E, 2020).

Seiring dengan meningkatnya pertambahan penduduk, kebutuhan air bersih pun meningkat, menurut data Badan Pusat Statistik Indonesiayang dirilis pada tahun 2013 - 2018 tercatat produksi air bersih Indonesia tahun 2018 sebanyak 4.879.050 $\mathrm{m}^{3}$ dengan jumlah penduduk 268 juta jiwa (Badan Pusat Statistik, 2019). 
Kualitas kimia pada air menjadi penting, hal tersebut dikarenakan mengandung bahan kimiawi pada air yang dapat berampak buruk terhadap kesehatan karena proses biokimiawi pada tubuh tidak terserap dengan baik. Adapun bahan kimiawi seperti halnya besi $(\mathrm{Fe})$, Nitrat $\left(\mathrm{NO}_{3}\right)$, arsenik dan logam lainnya dapat menjadi gangguan pada tubuh.

Pahruddin (2017) menyimpulkan bahwa dari dampak terpaparnya air yang mengandung bahan kimia seperti halnya cadmium, besi, dan mangan dalam bentuk kronis maupun akut. Dalam jangka waktu pendek, zat-zat tersebut dapat menimbulkan gangguan sistem pernafasan seperti lemas, batuk, sesak nafas, bronchopneumonia, edema par, dan cyanosis serta methemoglobinemia. Dampak penyimpangan parameter zat kimia adalah dapat meningkatkan reaktifitas pada pembuluh tenggorokan dan sensivitas pada penderita asma. Zat kimia bersifat racun terutama terhadap paru dengan diawali gangguan pada pernafasan.

Hasil penelitian Yosi Anjas Ningrum (2019) menunjukkan di Kampung Sapiria Kelurahan Lembo, Kecamatan Tallo, Kota Makassar pada air sumur gali penduduk ditemukan kandungan besi sebanyak 3,23 $\mathrm{mg} / \mathrm{l}$ dimana tidak memenuhi persyaratan a) yang telah ditetapkan oleh PERMENKES NO. 32 TAHUN 2017 untuk zat Besi (Fe) adalah $1 \mathrm{mg} / \mathrm{l}$.

Kualitas air bersih perlu menjadi perhatian utama dalam kesehatan karena apabila persyaratan yang telah ditetapkan oleh PERMENKES NO. 32 TAHUN 2017 tidak memenuhi dapat menyababkan masalah kesehatan dari tingginya kandungan zat besi (Fe) pada air sumur gali. Berdasarkan dari hasil penelitian Riskawati, dkk (2019), arang sekam padi berpengaruh menurunkan zat besi $(\mathrm{Fe})$ dengan berbagai berat konsentrasi 5,10 , dan $15 \mathrm{gr}$ sehingga dapat menurunkan dengan persentase $82 \%$ dengan kata lain semakin banyak kebutuhan arang sekam padi yang diperlukan maka semakin besar pula penurunan zat Besi $(\mathrm{Fe})$ pada air, sedangkan dari hasil peneilitian Rindy Antika, dkk (2019) dengan menggunakan arang tongkol jagung 1, 2, dan 3 gr pada setiap $100 \mathrm{ml}$ air sumur gali dengan persentase penurunan hingga $96 \%$.

Oleh karena itu diperlukan media sederhana yang mampu mengatasi permasalahan tingginya zat besi $(\mathrm{Fe})$ pada air sumur gali tersebut. yaitu dengan pemanfaatan media pengaruh arang sekam padi dan arang tongkol jagung sebagai media adsorben dalam penurunan zat besi $(\mathrm{Fe})$ pada air sumur gali. Kedua media yang digunakan banyak terdapat di Indonesia terkhusus daerah Sulawesi Selatan salah satunya kota Makassar serta media tersebut sangat mudah untuk didapatkan . Sehingga, dengan adanya sumber daya yang terdapat di masyarakat sendiri, mampu menangani permasalah yang terjadi di daerah tersebut.

\section{METODE \\ Jenis penelitian}

Jenis penelitian ini merupakan

Eksperimen semu (Quasi-Eperimental)

dengan pengujian terhadap sampel sebelum perlakuan dan setelah perlakuan.

\section{Desain, Tempat Dan Waktu}

Berdasarkan tujuan penelitian, yaitu mengetahui pengaruh arang sekam padi dan arang tongkol jagung sebagai media adsorben dalam penurunan zat Besi $(\mathrm{Fe})$ pada air sumur gali. Akan dipaparkan atau di ujikan dengan masing - masing ketebalan media $60 \mathrm{~cm}$ serta waktu kontak selama 90 menit dengan melakukan 3 kali replikasi.

Waktu penelitian dibagi menjadi dua tahap yaitu:

Tahap persiapan, yaitu penyusunan proposal dan seminar proposal pada bulan Januari 2021.

b) Tahap pelaksanaan, yaitu kegiata penelitian dilaksanakan pada bulan Februari - April 2021.

Yang dimana lokasi penelitian yaitu bertempat di jurusan kesehatan lingkungan poltekkes kemenkes makassar

\section{LANGKAH-LANGKAH PENELITIAN}

Proses Pembuatan Arang Sekam Padi Dan Arang Tongkol Jagung:

Siapkan sekam padi dan tongkol jagung yang telah dicuci dan dikeringkan di bawah matahari langsung. Untuk tongkol jagung dipotong - potong kecil $5-10 \mathrm{~cm}$. Masukkan media sekam padi dan tongkol jagung kedalam tungku pembakaran dengan terpisah hingga proses pengarangan (karbonisasi) keseluruhan media merata dan sempurna hingga asap yang keluar berwarna putih. Lakukan pengadukan masing - masing media setiap 30 menit dalam waktu 2 jam. Arang yang dihasilkan dari kedua media selama proses pembakaran tersebut di cuci menggunakan air bersih kemudian dikeringkan dengan suhu ruang, Aktifkan 
secara kimia dengan aktivasi larutan Asam Clorida $(\mathrm{HCl}) 50 \mathrm{ml} / 1$ Liter Aquadest untuk pengenceran kemudian didiamkan selama $1 \times 24$ jam pada suhu ruang dan dibilas kembali menggunakan aquadest. Lanjutkan dengan aktivasi basa menggunakan larutan Natrium Hidroksida $(\mathrm{NaOH}) 80 \mathrm{gr} / 1$ Liter Aquadest untuk pengenceran serta diamkan selama 1x24 jam dengan suhu ruang. Hasil perendaman kemudian dilakukan pencucian menggunakan aquades kemudian arang aktif yang telah direndam dikeringkan.

Pelaksanaan Eksperimen:

Siapkan alat dan bahan yang akan di gunakan dalam pengolahan. Sampel air sumur gali diambil untuk dilakukan pengujian awal terhadap zat Besi (Fe), pH, serta suhu. sebelum dilakukannya pengolahan, sampel air sumur gali di masukkan pada bak penampungan atau reservoir dengan volume air sebesar 60 liter yang dimana pada bak tersebut memiliki tinggi 3,5 m diatas wadah perlakuan. Sebelum air di alirkan, dengan gaya gravitasi wadah berukuran $1 \mathrm{~m}$ dengan diameter 4 inci diisi dengan masing - masing media dengan ketebalan $60 \mathrm{~cm}$ sampai padat. Alirkan air dengan menggunakan metode saringan pasir cepat, setelah itu didiamkan selama 90 menit sebelum keluar pada outlet wadah penampungan. Setelah melalui proses pengolahan sampel air sumur gali di ambil untuk dilakukan pameriksaan zat Besi (Fe), pH, dan suhu, Lakukan sebanyak 3 kali replikasi pada masing-masing media dalam rangka validasi hasil penelitian.

\section{PENGOLAHAN DAN ANALISIS DATA}

Data yang diolah dalam penelitian kali ini menggunakan alat bantu seperti Laptop / Komputer, kalkulator dan alat tulis lainnya. Dalam Analisa data menggunakan data yang didapatkan hasil pemeriksaan di laboratorium serta menganalisa secara deskriktif untuk mencari persentasi penurunan pada Zat Besi (Fe). Analisa data menggunakan statistik deskriptif SPSS untuk melihat adanya perbedaan kadar zat Besi (Fe) sebelum maupun setelah perlakuan menggunakan arang sekam padi dan arang tongkol jagung.

\section{HASIL}

Zat besi ( $\mathrm{Fe}$ ) merupakan tujuan utama yang akan di intervensi dalam penelitian kali ini dengan pengaruh arang sekam padi yang telah melalui proses aktivasi serta beberapa tahap dalam perlakuannya sehingga dapat dilihat tingkat perbandingan hasil sebelum dan setelah perlakuan sebagai berikut.

Berdasarkan pada Tabel 1, dapat diketahui bahwa hasil pemeriksaan air sumur gali menggunakan pengaruh arang sekam padi dalam penurunan kadar zat besi $(\mathrm{Fe})$ dinyatakan bahwa sebelum perlakuan yaitu diperoleh kadar zat besi ( $\mathrm{Fe}$ ) dengan ratarata sebanyak $11,4 \mathrm{mg} / \mathrm{l}$ dan pada kontrol terdapat kadar zat besi dengan rata-rata 9,2 $\mathrm{mg} / \mathrm{l}$ sehingga yang didapatkan setelah perlakuan melalui 3 kali replikasi kadar zat besi menurun dengan rata-rata $0 \mathrm{mg} / \mathrm{l}$ dengan persentase penurunan sebesar $100 \%$.

Berdasarkan pada tabel 2 dapat diketahui bahwa hasil pemeriksaan setelah perlakuan dengan menggunakan pengaruh media arang tongkol jagung terdapat kadar zat besi pada sampel awal sebelum perlakuan yaitu rata-rata $11,4 \mathrm{mg} / \mathrm{l}$ dan pada kontrol terdapat $9,2 \mathrm{mg} / \mathrm{l}$ sehingga dengan melalui proses perlakuan terjadi penurunan kadar zat besi $(\mathrm{Fe})$ dengan rata-rata yang didapatkan sebesar 0,2 mg/l dimana pada replikasi kedua memiliki kandungan yang paling tinggi setelah perlakuan dengan kadar zat besi sebesar $0,6 \mathrm{mg} / \mathrm{l}$ sehingga pada perlakuan tersebut terjadi tingkat penurunan dengan rata-rata persentase sebesar $98.5 \%$.

$\mathrm{pH}$ dan suhu merupakan variabel pengganggu pada penelitian kali ini dalam penurunan zat besi $(\mathrm{Fe})$ pada air sumur gali dengan media arang tongkol jagung sehingga dapat dilihat hasil pengukuran sebagai berikut

Berdasarkan tabel 3, dapat diketahui hasil rata-rata pemeriksaan pada $\mathrm{pH}$ yaitu rata-rata sebesar 6,98 dan suhu dengan ratarata $28,4^{\circ} \mathrm{C}$ sehingga masih dalam batas yan dipersyaratkan sesuai Permenkes No.32 tahun 2017 tentang pengawasan kualitas air bersih.

Berdasarkan dari hasil penelitian yang telah dilakukan dengan menggunakan arang sekam padi dan arang tongkol jagung untuk menurunkan kadar Zat Besi (Fe) pada air sumur gali yang terletak di Kampung Sapiria Kelurahan Lembo Kecamatan Tallo Kota Makassar dan pemeriksaan sampel dilakukan di Laboratorium Kesehatan Lingkungan Jl. Wijaya Kusuma 1 No.2 Kompleks Kesehatan Banta-Bantaeng, dengan menggunakan 3 kali replikasi maka di peroleh hasil rata-rata sebelum dan setelah perlakuan dengan menggunakan pengaruh arang sekam padi dan arang 
tongkol jagung sebagai media adsorben sebagai berikut.

Berdasarkan Gambar 1 dapat diketahui bahwa kadar zat besi (Fe) pada air sumur gali setelah dilakukan nya perlakuan, kadar zat besi $(\mathrm{Fe})$ mengalami peningkatan penurunan berdasarkan pada gambar diatas yaitu, arang sekam padi menurun sampai 0 $\mathrm{mg} / \mathrm{l}$ sehingga persentase penurunan sebesar $100 \%$ sedangkan arang tongkol jagung menurun sampai $0,2 \mathrm{mg} / \mathrm{l}$ dengan persentase penurunan sebesar $98,5 \%$.

Berikut ini merupakan hasil dari anaisa data dengan menggunakan uji Deskriptif SPSS untuk mengetahui ada tidaknya pengaruh arang sekam padi dan arang tongkol jagung yang digunakan sebagai intervensi atau perlakuan pada penurunan kadar zat besi ( $\mathrm{Fe}$ ) pada air sumur gali

Berdasarkan dari data tersebut dapat dilihat bahwa perbandingan antara sebelum perlakuan dengan setelah perlakuan menggunakan kedua media, dilihat dari nilai rata-rata mean sebelum perlakuan didapatkan 11.50 sedangkan setelah perlakuan dengan menggunakan arang sekam padi rata-rata mean yang diperoleh adalah 0.00 dan arang tongkol jagung dengan rata-rata mean 0.20 .

\section{PEMBAHASAN}

Telah dilakukan peneltian eksperimen mengenai pengaruh arang sekam padi dan arang tongkol jagung sebagai media adsorben dalam penurunan zat besi $(\mathrm{Fe})$ pada air sumur gali dengan metode adsorpsi (penjerapan). Penelitian ini menggunakan arang sekam padi dan arang tongkol jagung yang telah diaktivasi secara kimia dengan menggunakan larutan $\mathrm{HCl}$ $50 \mathrm{ml} / 1$ Liter aquadest dan $\mathrm{NaOH} 80 \mathrm{gr} / 1$ Liter Aquadest yang kemudian di kontakkan secara langsung pada penyaringan secara up flow menggunakan metode adsorpsi dengan tingkat ketebalan media masing masing $60 \mathrm{~cm}$ dalam waktu 90 menit pada sampel air sumur gali.

\section{Penurunan Kadar Zat Besi (Fe) Pada Air Sumur Gali Dengan Menggunakan Media Arang Sekam Padi}

Setelah dilakukan pemeriksaan zat besi dapat diketahui bahwa arang sekam padi dapat menurunkan zat besi (Fe) pada air sumur gali. Hasil pemeriksaan awal zat besi $(\mathrm{Fe})$ yang cukup tinggi dengan rata-rata sebesar 11,4 mg/l dan kontrol sebesar 9,2 $\mathrm{mg} / \mathrm{l}$ setelah dilakukan perlakuan yaitu dengan cara mengontakkan arang sekam padi yang telah diaktivasi dengan ketebalah masing-masing media $60 \mathrm{~cm}$ serta waktu kontak selama 90 menit pada sampel air sumur gali, maka diketahui bahwa rata-rata penurunan yang diperoleh dari 3 kali replikasi tersebut sebesar $100 \%$.

Dari hasil perlakuan dalam penurunan zat besi $(\mathrm{Fe})$ pada air sumur gali menggunakan media arang sekam padi, diperoleh nilai $\mathrm{pH}$ dengan rata-rata 6,94 dan suhu dengan rata-rata $28,2^{\circ} \mathrm{C}$ sehingga nilai $\mathrm{pH}$ masih dalam batas sesuai permenkes no. 32 tahun 2017 yaitu $\mathrm{pH}$ 6,5-8,5, sementara suhu yang masih optimum dikarenakan peenelitian tersebut dilaksanakan pada siang hari sehingga mengikut dengan temperatur udara.

Tinggi rendahnya $\mathrm{pH}$ air akan mempengaruhi terhadap kadar zat besi $(\mathrm{Fe})$ pada air sumur gali, apabila $\mathrm{pH}$ air rendah akan berakibat terjadinya proses korosifitas sehingga menyebabkan larutnya besi dan logam lainnya yang terkandung pada air, begitupun dengan suhu yang tinggi menyebabkan menurunnya kadar $\mathrm{O}_{2}$ sehingga dapat menguraikan mineral sehingga kelarutan Fe dalam air tinggi.

Pada penerapan perlakuan ini tidak terlepas dari pemakaian alat penyaringan sederhana secara up flow dengan menggunakan metode adsorpsi, hal tersebut sangat berperan penting dalam penurunan zat besi pada air sumur gali ditambah lagi dari tingkat ketebalan media serta waktu kontak yang di tetap kan menjadi sangat efektif dalam menurunkan zat besi $(\mathrm{Fe})$ pada air sumur gali.

Hal tersebut dikarenakan dari proses pengaktivasian menggunakan $\mathrm{HCl}$ dan $\mathrm{NaOH}$ serta waktu kontak yang sempurna mengakibatkan arang tersebut dapat menjadi adsorben atau dapat menjerap zat besi sehingga terjadi penurunan yang signifikan atau dengan menggunakan metode adsorpsi dalam penerapan penyaringan kali ini. Adsorpsi adalah suatu proses yang terjadi ketika suatu fluida, cairan maupun gas, terikat pada suatu padatan atau cairan (zat penjerap, adsorben) (Syamsuddin S, 2019).

Terjadinya penurunan yang sangat signifikan kadar zat besi $(\mathrm{Fe})$ pada air sumur gali dipengaruhi oleh proses pengaktivasian arang yang dimana bertujuan untuk meningkatkan volume dan memperbesar diameter pori setelah mengalami proses karbonisasi dan meningkatkan penyerapannya. Pada umumnya karbon aktif 
Jurnal Sulolipu : Media Komunikasi Sivitas Akademika dan Masyarakat

Vol. 21 No.2 2021

e-issn : 2622-6960, p-issn : 0854-624X

dapat diaktivasi dengan dua cara yaitu aktifasi kimia dan aktivasi fisika.

Pada penelitian kali ini dalam penurunan zat besi ( $\mathrm{Fe}$ ) pada air sumur gali pengaktivasian media dilakukan dengan aktivasi kimia dengan menggunakan $\mathrm{HCl} 50$ $\mathrm{ml} / 1$ liter aquadest dan $\mathrm{NaOH} 80 \mathrm{gr} / 1$ liter aquadest sehingga daya menjerapnya dapat efektif dalam penurunan zat besi ( $\mathrm{Fe}$ ) pada air sumur gali.

Sampel air sumur gali yang disaring kedalam filter dengan sistem up flow yang dimana berisi media arang sekam padi dengan ketebalan $60 \mathrm{~cm}$ yang didiamkan selama 90 menit dapat memungkinkan proses oksidasi berjalan dengan baik. Terjadinya proses oksidasi zat besi yang terlarut melewati penyaringan secara up flow ditambah dengan media arang sekam padi sebagai adsorben yang dapat menjerap zat besi ( $\mathrm{Fe}$ ) yang terdapat dalam sampel air, menghasilkan endapan zat besi akan tertahan pada saringan, sehingga besi pada sampel air yang keluar dari penyaringan akan menurun.

Faktor utama yang menyebabkan tingginya zat besi (Fe) pada air sumur gali dapat dilihat dari segi konstruksi maupun lokasi dari sumur gali tersebut salah satu contonya yaitu jarak antara sumber pencemar dengan sumur gali berjarak kurang dari 11 meter sehingga bahan kimia yang terkandung pada sumber pencemar seperti sulfur $\left(\mathrm{SO}_{2}\right)$ mencemari air sumur gali sehingga dapat menyebabkan korosifitas pada air. salah satu syarat konstruksi serta lokasi sumur gali adalah lokasi sumur gali berjarak horisintal 11 meter ke arah hulu dari aliran tanah dari sumber pengotoran, seperti resapan dari tangki septik, kakus, empang, lubang galian untuk sampah, dan lain-lain (Handayani, R, 2019)

Penelitian Riskawati, Rahmi Amir, \& Herlina Miun. (2019) yang melakukan pengolahan zat besi (Fe) menggunakan arang sekam padi pada air sumur bor sejalan dengan penelitian kali ini dimana penelitian tersebut menggunakan media arang sekam padi dengan berbagai macam varias berat menggunakan metode adsorpsi sehingga dapat menurunkan zat besi (Fe) sampai $82 \%$ dengan kata lain semakin banyak jumlah arang sekam padi yang digunakan maka semakin efektif dalam penurunan zat besi (Fe).

Ketiga percobaan yang dilakukan pada penelitian ini dengan menggunakan arang sekam padi, menunjukkan kadar zat besi (Fe) turun sampai 100\%, hal ini dikarenakan pengaruh ketebalan media dan waktu kontak selama 90 menit sangat berperan dalam menurunkan zat besi (Fe) serta proses pengaktivasian arang yang sempurna sehingga pada saat perlakuan atau intervensi efektif dapat menurunkan zat besi (Fe) pada air sumur gali sebesar 100\%.

Selain dari sampel air sumur gali yang telah melalui perlakuan tidak terlepas dari proses pangaktivasian arang yang sempurna sehingga media arang sekam padi yang digunakan dapat menurunkan kadar zat besi (Fe) dengan persentase penurunan $100 \%$. Karbon aktif atau arang yang telah diaktivasi dengan menggunakan bahanbahan kimia mengandung 5-15\% air, 2-3\% abu, dan sisanya terdiri dari karbon serta pori-pori yang terbuka sehingga memiliki daya adsorpsi yang tinggi terhadap zat, warna, dan bau (Syamsuddin S, 2019).

Penurunan kadar zat besi (Fe) pada air sumur gali dengan menggunakan arang sekam padi sangat berpengaruh dikarenakan komposisi yang terkandung pada sekam padi dapat membantu dari proses adsorpsi air sumur gali. Arang sekam padi memiliki kandungan silika (SiO2) yang cukup tinggi yaitu $15-20 \%$, $17-20 \%$ abu yang mengandung 90-98 silika serta karbon (zat arang) sebesar 1,33\% (Hadiutomo,K, 2019).

Dengan demikian merujuk dari hasil pemeriksaan tersebut, Arang sekam padi berpengaruh menurunkan kadar zat besi (Fe) pada air sumur gali dengan penurunan setelah perlakuan $0 \mathrm{mg} / \mathrm{l}$ sehingga dikatakan dapat memeuhi standar baku mutu sesuai Permenkes No.32 tahun 2017 tentang persyaratan kualitas air bersih yang dimana kadar zat besi yang diperbolehkan pada air bersih maksimal 1,0 mg/l. 


\section{Penurunan Kadar Zat Besi (Fe) Pada Air Sumur Gali Dengan Menggunakan Media Arang Tongkol Jagung \\ Air yang tercemar dari kadar zat besi} (Fe) yang tinggi akan menimbulkan berbagai macam dampak negatif. Kadar zat besi dibatasi dengan maksimum $1 \mathrm{mg} / \mathrm{l}$ sesuai permenkes no. 32 tahun 2017. Hal tersebut ditetapkan berdasarkan masalah warna, rasa, serta menimbulkan kerak yang menempel pada sistem perpipaan atau estetika, sama halnya dengan manusia yang pastinya memerlukan zat besi dengan kadar tertentu, sehingga kadar yang berlebihan perlu dihindari (Mulyani, 2017).

Kadar zat besi yang tinggi pada air dapat menimbulkan dampak negatif pada tubuh, disamping itu peran zat besi sangat dibutuhkan oleh manusia dikarenakan adanya reaksi oksidasi dan reduksi, kekurangan zat besi terjadi dapat menyebabkan gangguan pencernaan karena mengonsumsi makanan yang kurang mengandung zat besi sehingga terjadi gangguan adsorbsi dalam tubuh.

Merujuk dari tabel hasil pemeriksaan kadar zat besi $(\mathrm{Fe})$ dapat diketahui bahwa arang tongkol jagung berpengaruh dalam menurunkan zat besi (Fe) dengan persentase penurunan sebesar $98,5 \%$ yang dimana dari ketiga replikasi tersebut terdapat kandungan zat besi (Fe) tertinggi pada replikasi kedua yaitu $0,6 \mathrm{mg} / \mathrm{l}$, dengan demikian rata-rata penurunan zat besi $(\mathrm{Fe})$ setelah perlakuan yaitu $0,2 \mathrm{mg} / \mathrm{l}$.

Faktor utama yang menyebabkan tingginya zat besi (Fe) pada air sumur gali dilihat dari konstruksi maupun lokasi dari sumur gali tersebut karena berdampak pada tinggi rendahnya tingkat pencemar seperti halnya zat besi $(\mathrm{Fe})$ dan logam-logam lainnya.

Pada penelitian ini penerapan penyaringan dengan sistem aliran up flow dapat efektif menurunkan zat besi ( $\mathrm{Fe}$ ) pada air sumur gali dikarenakan dapat meminimalisir terjadinya kebuntuan pada media dan sistem seperti ini akan lebih mudah dalam penucian media ditambah dengan media arang tongkol jagung yang telah diaktivasi dengan ketebalan media 60 $\mathrm{cm}$ serta waktu kontak selama 90 menit sehingga dapat menurunkan kadar zat besi (Fe) secara efektif.

Disamping itu, pada penyaringan kali ini dengan menggunakan media arang tongkol jagung, kondisi fisik media tersebut sangat mudah jenuh dikarenakan komposisi media yang mudah remah atau mudah hancur ditambah dengan komposisi media yang tidak bisa bertahan atau terkena dengan air sehingga terjadinya perubahan warna sampel air tersebut setelah perlakuan.

Pencemaran zat Besi $(\mathrm{Fe})$ pada umumnya sering dijumpai oleh masyarakat yang menggunakan air dalam kehidupan sehari-hari salah satunya MCK (mandi cuci kakkus), salah satu contoh dampak dari tingginya zat besi $(\mathrm{Fe})$ pada air sumur gali yaitu jarak lokasi antara sumber pencemar (septic tank) dengan sumur gali berjarak kurang dari 11 meter sehingga bahan kimia yang terkandung pada sumber pencemar (septic tank) seperti sulfur $\left(\mathrm{SO}_{2}\right)$ dapat mencemari air sumur gali sehingga dapat menyebabkan tingginya korosifitas pada air. salah satu syarat konstruksi serta lokasi sumur gali adalah lokasi sumur gali berjarak horisintal 11 meter ke arah hulu dari aliran tanah dari sumber pengotoran, seperti resapan dari tangki septik, kakus, empang, lubang galian untuk sampah, dan lain-lain (Handayani, R, 2019)

Replikasi II memiliki kadar zat besi ( $\mathrm{Fe}$ ) yang tinggi setelah perlakuan dari ketiga replikasi sebesar $0,6 \mathrm{mg} / \mathrm{l}$, hal tersebut disebabkan karena kadar zat besi $(\mathrm{Fe})$ pada sampel awal pemeriksaan yang tinggi direplikasi kedua sebesar $16.8 \mathrm{mg} / \mathrm{l}$ sehingga media arang tongkol jagung tidak mampu mengadsorpsi dengan baik yang berakibat masih terdapat kadar zat besi ( $\mathrm{Fe}$ ) setelah perlakuan dengan kadar sebesar $0.6 \mathrm{mg} / \mathrm{l}$.

Merujuk dari hasil pemeriksaan kadar zat besi $(\mathrm{Fe})$ setelah perlakuan, tidak terlepas dari $\mathrm{pH}$ dan suhu sebagai variabel pengganggu pada penelitian kali ini sehingga diperoleh nilai $\mathrm{pH}$ dengan rata-rata 6,98 dan suhu dengan rata-rata $28,4^{\circ} \mathrm{C}$ sehingga nilai $\mathrm{pH}$ masih dalam batas sesuai dengan permenkes no. 32 tahun 2017 yaitu $\mathrm{pH}$ 6,58,5 , sementara suhu yang masih optimum dikarenakan peenelitian tersebut dilaksanakan pada siang hari sehingga mengikut dengan temperatur udara di lingkungan tersebut.

Tinggi rendahnya $\mathrm{pH}$ pada air dapat mempengaruhi terhadap kadar zat besi $(\mathrm{Fe})$ pada air sumur gali, apabila $\mathrm{pH}$ air rendah akan berakibat terjadinya proses korosifitas sehingga menyebabkan larutnya besi dan logam lainnya yang terkandung pada air, begitupun dengan suhu yang tinggi menyebabkan menurunnya kadar $\mathrm{O}_{2}$ sehingga dapat menguraikan mineral sehingga kelarutan Fe dalam air tinggi. 
Jurnal Sulolipu : Media Komunikasi Sivitas Akademika dan Masyarakat

Vol. 21 No.2 2021

e-issn : 2622-6960, p-issn : 0854-624X

Berdasarkan dari hasil pemeriksaan zat besi $(\mathrm{Fe})$ setelah perlakuan dengan tiga kali replikasi, terdapat kadar zat besi $(\mathrm{Fe})$ yaitu dengan rata-rata $0,2 \mathrm{mg} / \mathrm{l}$ dengan demikian dapat dikatakan kadar tersebut masih memenuhi standar baku mutu sesuai Permenkes No.32 Tahun 2017 yaitu 1,0 mg/l.

Hasil penelitian Rindy Antika, dkk (2019) tentang evektivitas karbon tongkol jagung dalam menurunkan kadar besi $(\mathrm{Fe})$ dan mangan (Mn) pada air sumur gali di Desa Amplas Kecamatan Percut Sei Tuan Kabupaten Deli serdang sejalan dengan penelitian ini yang menyatakan bahwa arang tongkol jagung dapat menurunkan zat besi (Fe) setelah menambahkan media dengan beberapa variasi berat yang berbeda sehingga persentase penurunan yang di dapatkan yaitu hingga $96 \%$.

Penelitian ini juga sejalan dengan teori yang didapatkan bahwa arang tongkol jagung mampu menjadi media adsorben (penjerap) dikarenakan memiliki komponen yang baik digunakan salah satunya mengandung abu yaitu biji utuh $0,8 \%$, endosperm $0,3 \%$, embrio $32,2 \%$, kulit ari $0,8 \%$ dan ujung biji 1,6\% sehingga baik digunakan sebagai media penjerap logamlogam dalam hal ini zat besi (Meta Mahendrata dan abu bakar tawali, (2016) dalam Syamsia dan Abubakar Idhan, 2019).

Maka dari itu hasil kadar zat besi ( $\mathrm{Fe})$ setelah perlakuan kedua media arang sekam padi dan arang tongkol jagung, arang sekam padi sangat berpengaruh dalam menurunkan kadar zat besi $(\mathrm{Fe})$ pada air sumur gali dengan persentase penurunan rata-rata $100 \%$ dibandingkan arang tongkol jagung yang berpengaruh menurunkan zat besi $(\mathrm{Fe})$ dengan persentase penurunan rata-rata $98.5 \%$.

\section{KESIMPULAN}

Berdasarkan dari hasil penelitian yang dilakukan dapat disimpulkan sebagai berikut:

1. Arang sekam padi berpengaruh dalam menurunkan zat besi (Fe) pada air sumur gali dengan persentase penurunan $100 \%$.

2. Arang tongkol jagung berpengaruh dalam menurunkan zat besi ( $\mathrm{Fe}$ ) pada air sumur gali dengan persentase penurunan $98 \%$

3. Media yang paling berpengaruh dalam penurunan zat besi $(\mathrm{Fe}$ ) pada air sumur gali kali ini adalah arang sekam padi dengan persentase penurunan 100\% dibandingkan dengan arang tongkol jagung dengan persentase penurunan $98 \%$.

\section{SARAN}

1. Untuk masyarakat dapat memanfaatkan kedua media selain mudah didapatkan media tersebut menjadi alternatif dalam pemecahan masalah terkhusus tingginya zat besi $(\mathrm{Fe})$ pada air bersih yang melebihi standar kualitas.

2. Untuk penelitian selanjutnya dalam penggunaan arang tongkol jagung dapat menjadi pertimbangan dikarenakan sifat fisik dari media tersebut sangat mudah jenuh sehingga air dapat berubah warna serta dalam pengaktivasian arang menggunakan bahan-bahan alternatif yang mudah dijangkau oleh masyarakat.

\section{DAFTAR PUSTAKA}

Badan Pusat Statistik. (2019). /Catalog: 6206001. (Online). https://www.bps.go.id/publication/2019/12/24/e3be82175162b2dd1fe7b925/statistikair-bersih-2013--2018.html. Diakses pada 22 Desember 2020

Cahyono, Try. 2019. Kesehatan Lingkungan Teori dan Aplikasi. Jakarta: Buku kedokteran EGC Hadiutomo, Kusno. 2019. Membangun Kawasan Persawahan Padi Modern "Solusi Ketahanan Pangan Ke Depan". Bogor: IPB Press. (Online).https://books.google.co.id/books?id=E6PVDwAAQBAJ\&printsec=frontcover\& $\mathrm{dq}=$ Membangun+Kawasan+Persawahan+Padi+Modern+\%E2\%80\%9CSolusi+Ketaha nan+Pangan+Ke+Depan\%E2\%80\%9D\&hl=id\&sa=X\&ved=2ahUKEwjg55Cy9PTtAhVa WysKHefnAvcQ6AEwAHoECAEQAg\#v=onepage\&q=Membangun\%20Kawasan\%20P ersawahan\%20Padi\%20Modern\%20\%E2\%80\%9CSolusi\%20Ketahanan\%20Pangan \%20Ke\%20Depan\%E2\%80\%9D\&f=false. Diakses pada 23 Desember 2020

Handayani, Rezqi. 2019. Buku Ajar IImu Kesehatan Masyarakat. Malang: CV IRDH. (Online). https://books.google.co.id/books?id=lqzuDwAAQBAJ\&pg=PR1\&dq=Buku+Ajar+llmu+ Kesehatan+Masyarakat\&hl=id\&sa=X\&ved=2ahUKEwjt7I2P9fTtAhUIOSsKHfYtCG8Q6 
Jurnal Sulolipu : Media Komunikasi Sivitas Akademika dan Masyarakat

Vol. 21 No.2 2021

e-issn : 2622-6960, p-issn : 0854-624X

AEwBXoECAAQAg\#v=onepage\&q=Buku\%20Ajar\%20Ilmu\%20Kesehatan\%20Masyar akat\&f=false. Diakses pada 22 Desember 2020

Hariyani, S,. dan Usman Fadly., dan Kurniawan, E, B. 2020. Prasarana Wilayah Dan Kota. Penebit: Qiara Media. https://books.google.co.id/books?id=TTbfDwAAQBAJ\&printsec=frontcover\&dq=Prasar ana+Wilayah+Dan+Kota\&hl=id\&sa=X\&ved=2ahUKEwj3x4K49vTtAhVEeysKHRsDCT MQ6AEwAHoECAQQAg\#v=onepage\&q=Prasarana\%20Wilayah\%20Dan\%20Kota\&f=f alse. Diakses pada 27 Desember 2020

Mahendradatta meta, et al. 2016. Jagung Dan Diverifikasi Produk Olahannya. Makassar: Masegena press.

Mulyani, H. 2017. Penuntun Praktik Ananlisis Dan Optimasi System Penyehatan Air Minum. Yogyakarta: Pustaka Pelajar

Nugraheny, D, E. 2020. Data Kependudukan 2020: Penduduk Indonesia 268.583.016 Jiwa. Dalam Kompas.com (Online). https://nasional.kompas.com/read/2020/08/12/15261351/data-kependudukan-2020penduduk-indonesia-268583016¡iwa?page=all\#: :text=JAKARTA\%2C\%20KOMPAS.com\%20\%2D\%20Kementerian,J uni\%20sebanyak\%20268.583.016\%20jiwa. Diakses pada 22 Desember 2020

Pahruddin, M. (2017). Risiko Pajanan Logam Berat Pada Air Sungai. Jurnal Kesehatan Lingkungan: Jurnal Dan Aplikasi Teknik Kesehatan Lingkungan, 14(2), 525. https://doi.org/10.31964/jkl.v14i2.47. diakses pada 22 Desember 2020

Permatasari, W. M. (2016). Hubungan antara Status Gizi, Siklus dan Lama Menstruasi dengan Kejadian Anemia Remaja Putri di SMA Negeri 3 Surabaya. Perpustakaan Universitas Airlangga, 1-62. diakses pada 23 Januari 2021

Rachmat, M. 2017. Metodologi Penelitian Gizi dan Kesehatan. Jakarta: Buku Kedokteran EGC.

Rahayu, A, et al. 2019. Buku Referensi Metode ORKES-KU (Report Kesehatanku) Dalam Mengidentifikasi Potensi Kejadian Anemia Gizi Pada Remaja Putri. Yogyakarta: CV Mine.(Online). $\quad$ http://kesmas.ulm.ac.id/id/wp-content/uploads/2019/04/BUKUMETODE-ORKES-KU-RAPORT-KESEHATANKU.pdf.diakses pada 23 Januari 2021.

Republik Indonesia. 2017. Permenkes Nomor 32 Tahun 2017. Kementerian Kesehatan Republik Indonesia. Jakarta

Rindy A, S. D., \& Pane, P. Y. (2019). Efektivitas Karbon Aktif Tongkol Jagung dalam Menurunkan Kadar Besi $(\mathrm{Fe})$ dan Mangan ( $\mathrm{Mn}$ ) pada Air Sumur Gali di Desa Amplas Kecamatan Percut Sei Tuan Kabupaten Deli Serdang. Jurnal Kesehatan Global, 2(2), 82. https://doi.org/10.33085/jkg.v2i2.4263. diakses pada 12 Desember 2020.

Riskawati, Rahmi Amir, \& Herlina Miun. (2019). Efektivitas Arang Sekam Padi Dalam Menurunkan Kadar Besi (Fe) Pada Air Sumur Bor Di Desa Padangloang Kabupaten Pinrang. Jurnal IImiah Manusia Dan Kesehatan, 2(1), 156-163. https://doi.org/10.31850/makes.v2i1.132

Ronny, \& Hasim, A. H. (2018). Effectiveness of multiple tray-aerators in reducing iron ( $\mathrm{Fe}$ ) water wells in Gowa Regency, Indonesia. Ecology, Environment and Conservation, 24(1), 2225. https://doi.org/10.31227/osf.io/nvpbh

Ronny, Muntu. 2019. Penyehatan Air. Politeknik Kesehatan Jurusan Kesehatan Lingkungan. Makassar

Rossa, Vania,. dan Nadia, Fista. 2018. Ada 33,4 juta Penduduk Indonesia Kekurangan Air Bersih. Dalam Suara.com (online). https://www.suara.com/health/2018/11/23/162639/ada-334-juta-penduduk-indonesiakekurangan-air-bersih?page=all. Diakses pada 15 Desember 2020.

Sebayang, P., Muljadi., tetuko. A,P., Kurniawan, C., Sari, A,Y., dan Nurdiansyah, L, F. 2015. Teknologi Pengolahan Air Kotor dan Payau Menjadi Air Bersih dan Layak Minum. Jakarta: Lembaga Ilmu Pengetahuan.

Suryokusumo, B. S., dan Yatnawijaya, B. S. 2018. Dasar Perencanaan Plambing dan Sistem Distribusi Air Bidang Arsitektur. Malang: UB Press. (Online). https://books.google.co.id/books?id=MSOJDwAAQBAJ\&printsec=frontcover\&dq=Das ar+Perencanaan+Plambing+dan+Sistem+Distribusi+Air+Bidang+Arsitektur\&hl=id\&sa $=$ X\&ved=2ahUKEwig1ti05 TtAhVJWHOKHU75CMoQ6AEwAHoECAIQAg\#v=onepage\& 
Jurnal Sulolipu : Media Komunikasi Sivitas Akademika dan Masyarakat

Vol. 21 No.2 2021

e-issn : 2622-6960, p-issn : 0854-624X

q=Dasar\%20Perencanaan\%20Plambing\%20dan\%20Sistem\%20Distribusi\%20Air\%20 Bidang\%20Arsitektur\&f=false. Diakses pada 22 Desember 2020

Syamsuddin dkk. 2019. Kesehatan Lingkungan Indonesia : Teori Dan Aplikasi. Jakarta : Buku Kedokteran EGC.

Syamsia. 2019. Produksi Benih Jagung Hibrid. Makassar: Nas Media Pustaka.

Yosi, A,N . 2019. Efektifitas Media Filter Cangkang Kerang (Anadara granosa) dan Ion Exchanger dalam Menurunkan Kadar Besi (Fe) pada Air Sumur Gali. Skripsi . Jurusan Kesehatan Lingkungan Politeknik kesehatan kementerian kesehatan Makassar. Makassar. 
Jurnal Sulolipu : Media Komunikasi Sivitas Akademika dan Masyarakat Vol. 21 No.2 2021

e-issn : 2622-6960, p-issn : 0854-624X

Tabel 1

Penurunan Kadar Zat Besi (Fe) Menggunakan Media Arang Sekam Padi Tahun 2021.

\begin{tabular}{ccccccc}
\hline & Pengulangan & \multicolumn{2}{c}{$\begin{array}{c}\text { Sebelum } \\
(\mathbf{m g} / \mathbf{l})\end{array}$} & $\begin{array}{c}\text { Sesudah } \\
(\mathbf{m g} / \mathbf{l})\end{array}$ & $\begin{array}{c}\text { Penurunan } \\
(\mathbf{m g} / \mathbf{l})\end{array}$ & $\%$ \\
\cline { 3 - 6 } & Awal & Kontrol & & & \\
\hline 1. & Replikasi I & 11 & 9 & 0 & 11 & 100 \\
2. & Replikasi II & 16,8 & 14 & 0 & 16,8 & 100 \\
3. & Replikasi III & 6,6 & 4,6 & 0 & 6,6 & 100 \\
\hline & Rata-Rata & $\mathbf{1 1 , 4}$ & $\mathbf{9 , 2}$ & $\mathbf{0}$ & $\mathbf{1 1 , 4}$ & $\mathbf{1 0 0}$ \\
\hline
\end{tabular}

Sumber: Data Primer

Tabel 2

Penurunan Kadar Zat Besi (Fe) Menggunakan Media Arang Tongkol Tahun 2021.

\begin{tabular}{ccccccc}
\hline No & Pengulangan & \multicolumn{2}{c}{$\begin{array}{c}\text { Sebelum } \\
(\mathbf{m g} / \mathbf{l})\end{array}$} & $\begin{array}{c}\text { Sesudah } \\
(\mathbf{m g} / \mathbf{l})\end{array}$ & $\begin{array}{c}\text { Penurunan } \\
(\mathbf{m g} / \mathbf{l})\end{array}$ & $\%$ \\
\cline { 3 - 4 } & & Awal & Kontrol & & & \\
\hline 1. & Replikasi I & 11 & 9 & 0 & 11 & 100 \\
2. & Replikasi II & 16,8 & 14 & 0,6 & 16,2 & 95,7 \\
3. & Replikasi III & 6,6 & 4,6 & 0 & 6,6 & 100 \\
\hline & Rata-Rata & $\mathbf{1 1 , 4}$ & $\mathbf{9 , 2}$ & $\mathbf{0 , 2}$ & $\mathbf{1 1 , 2}$ & $\mathbf{9 8 . 5}$ \\
\hline
\end{tabular}

Sumber: Data Primer

Tabel 3

Pemeriksaan pH dan Suhu Setelah Perlakuan Menggunakan Arang Tongkol Jagung

\begin{tabular}{cccccc}
\hline & & \multicolumn{2}{c}{ Arang Sekam Padi } & \multicolumn{2}{c}{$\begin{array}{c}\text { Arang Tongkol } \\
\text { Jagung }\end{array}$} \\
\cline { 3 - 6 } No & Pengulangan & $\mathbf{p H}$ & $\begin{array}{c}\text { Suhu } \\
\left({ }^{\circ} \mathbf{C}\right)\end{array}$ & $\mathbf{p H}$ & Suhu $\left({ }^{\circ} \mathbf{C}\right)$ \\
\hline 1. & Replikasi I & 7,02 & 27,6 & 7,04 & 28,9 \\
2. & Replikasi II & 6,85 & 28,5 & 6,98 & 28,6 \\
3. & Replikasi III & 6,95 & 28,7 & 6,92 & 27,7 \\
\hline & Rata-Rata & $\mathbf{6 , 9 4}$ & $\mathbf{2 8 , 4}$ & $\mathbf{6 , 9 8}$ & $\mathbf{2 8 , 4}$ \\
\hline
\end{tabular}

Sumber: Data Primer 
Jurnal Sulolipu : Media Komunikasi Sivitas Akademika dan Masyarakat Vol. 21 No.2 2021

e-issn : 2622-6960, p-issn : 0854-624X

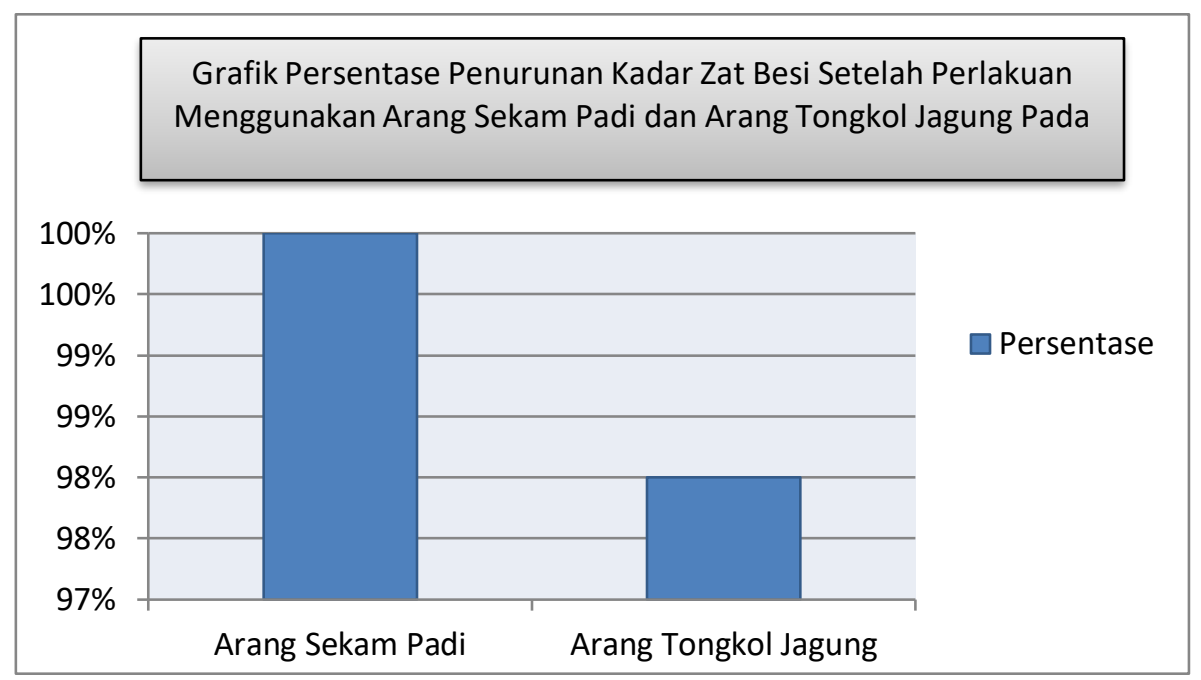

Gambar 1 Grafik Rata-Rata Penurunan Kadar Zat Besi Pada Air Sumur Gali Dengan Menggunakan Pengaruh Arang Sekam Padi dan Arang Tongkol Jagung Sebagai Media Adsorben

Tabel 4

Hasil Analisa Statistik Uji Deskriptif SPSS Pengaruh Arang Sekam Padi Dan Arang Tongkol Jagung Sebagai Media Adsorben Dalam Penurunan Zat Besi (Fe) Pada Air Sumur Gali

\begin{tabular}{cccc|c}
\hline & N & Mean & Std.Deviation & Standar error \\
\hline $\begin{array}{c}\text { Sebelum } \\
\text { perlakuan }\end{array}$ & 3 & 11.50 & 5.115 & 1.225 \\
Arang sekam padi & 3 & 0.00 & 0.000 & 0 \\
$\begin{array}{c}\text { Arang tongkol } \\
\text { jagung }\end{array}$ & 3 & 0.20 & 0.346 & 1.225 \\
Valid N (listwise) & 3 & & & \\
\hline
\end{tabular}

Sumber: Data Primer 